\title{
Hypertension predicts a poor prognosis in patients with esophageal squamous cell carcinoma
}

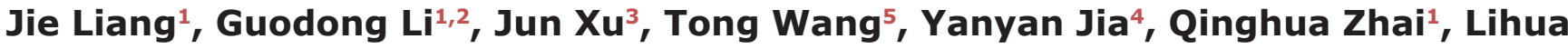 \\ Qiao ${ }^{4}$, Miao Chen ${ }^{4}$, Yajing Guo ${ }^{4}$ and Shujun Zhang ${ }^{4}$ \\ ${ }^{1}$ Department of Medical Records and Statistics, Shanxi Provincial Cancer Hospital, Taiyuan, Shanxi, China \\ ${ }^{2}$ Department of Hospital Administration, Shanxi Provincial Cancer Hospital, Taiyuan, Shanxi, China \\ ${ }^{3}$ Department of General Surgery, Shanxi Provincial Cancer Hospital, Taiyuan, Shanxi, China \\ ${ }^{4}$ Department of Medical Records and Follow-up, Shanxi Provincial Cancer Hospital, Taiyuan, Shanxi, China \\ ${ }^{5}$ Department of Health Statistics, School of Public Health, Shanxi Medical University, Taiyuan, Shanxi, China \\ Correspondence to: Guodong Li, email:314350829@qq.com \\ Jun XU, email: xujun_sxth@sina.com \\ Keywords: ESCC; hypertension; hypoxia; VEGF; esophagectomy \\ Received: June 22, 2017 Accepted: December 21,2017 Epub: January 01, 2018 Published: March 06, 2018 \\ Copyright: Liang et al. This is an open-access article distributed under the terms of the Creative Commons Attribution License 3.0 \\ (CC BY 3.0), which permits unrestricted use, distribution, and reproduction in any medium, provided the original author and source \\ are credited.
}

\section{ABSTRACT}

Background: We investigated the relationship between the preoperative hypertension and prognosis of esophageal squamous cell cancer (ESCC) patients who had underwent esophagectomy.

Results: We detected $52 \%$ patients with hypertension, including 317 patients with newly diagnosed hypertension and 194 patients with history of hypertension. Compared with patients of normal blood pressure, all patients with hypertension and newly diagnosed hypertension were observed to have worse overall and ESCC-specific survival outcome $(p<0.05)$. After adjusted in multivariate Cox regression analysis, hypertension (HR: 1.343, 95\% CI: 1.064, 1.695; HR: 1.315, 95\% CI: 1.039, 1.664) and newly diagnosed hypertension (HR: 1.414, 95\% CI: 1.095, 1.826; HR: 1.420, 95\% CI: $1.098,1.836)$ were inversely associated with overall and ESCC-specific survival outcome, respectively. While no association was found between history of hypertension and overall or ESCC-specific survival outcome (HR: 1.229, 95\% CI: 0.892, 1.694; HR: 1.132, 95\% CI: 0.812, 1.578).

Conclusions: Hypertension was an independent risk factor and resulted in inferior prognosis for ESCC patients who had underwent esophagectomy.

Methods: A total of 982 ESCC patients who had underwent esophagectomy from August 2010 to December 2015 were enrolled in our study with a follow up of $\mathbf{6}$ years. The Kaplan-Meier method and log-rank test were respectively used to calculate and compare survival rate, and Cox proportional hazards regression model was applied to identify independent prognostic factors.

\section{INTRODUCTION}

Esophageal cancer (EC) with higher incidence and mortality has been still an aggressive malignant tumors worldwide [1]. EC is one of the highest prevalence tumors and the fourth leading cause of cancer-related death in China, and its age-standardized 5-year survival rate was only $20.9 \%$ [2]. The esophageal squamous cell carcinoma (ESCC) is the predominant histological type and accounts for over $90 \%$ of EC in China $[1,3]$. Up until now, surgical resection has remained the mainstream treatment for ESCC. However, the long-term outcomes after esophagectomy are still not ideal, with the average 5 -year survival rates at $20-30 \%[4,5]$. Therefore, it is necessary to detect the 
risk factors associated to prognosis of ESCC patients after surgical resection and further adopting adjunctive therapy to make it control.

Hypertension, a chronic disease, is among other acknowledged key risk factors for stroke and coronary heart disease. As reported, approximately $40 \%$ of adults above 25 years old had been diagnosed with hypertension in worldwide [6]. The influence of hypertension has been a field of investigation for long-time. Many studies have separately reported hypertension as an important risk factor for elevated cancer incidence and mortality. A combined analysis of the Nurses' Health Study (NHS) and the Health Professionals Follow-up Study (HPFS) cohorts in the United States have examined hypertension as an independent risk factor of renal cell carcinoma incidence in a prospective study [7]. Other researchers identified that hypertension is associated with incidence and progression of kidney cancer $[8,9]$. In addition, the results from other large prospective studies suggested that elevated blood pressure (BP) might be associated with an increased risk of cancer incidence, including fatal malignant melanoma [10, 11], pancreatic [12], endometrial [13], brain and bladder cancer $[14,15]$. Observational studies have shown results for the relationship between hypertension and higher risk of cancer mortality. A meta-analysis based on 10 longitudinal studies of in total 47119 participants, hypertension is related to a $23 \%$ increased risk of cancer mortality [16]. The positive risk has been found that hypertension is associated with an increased risk of death from prostate cancer [17-20]. In a historical cohort study of women diagnosed with breast cancer, hypertension is associated with total and breast cancer-specific mortality [21]. Another study including 17498 participants showed that BP is inversely associated with mortality from leukemia and pancreatic cancer but positively associated with mortality attributed to liver and rectal cancer [10]. Since hypertension is a risk factor of cancer incidence and mortality, we supposed whether this trend could be found in hypertension and prognosis of cancer. However, fewer of studies have identified the relationship between hypertension and prognosis of cancer directly. This relationship is more often to be explored indirectly by taking hypertension as a trait of metabolic syndrome, which has been identified negatively associated with prognosis of cancer, such as breast cancer [22] and renal cell carcinoma [23]. Therefore, this study was designed to investigate the association between preoperative hypertension and prognosis among patients with ESCC.

\section{RESULTS}

\section{Patients baseline characteristics and survival outcome}

In the current study, the overall prevalence of hypertension in 982 patients was $52.0 \%$. Among them, 317 were newly diagnosed hypertension and 194 had history of hypertension including 34.5\% well-controlled and 65.5\% poorly-controlled hypertension. Distributions of baseline characteristics based on different hypertension status were shown in Table 1. Patients with history of hypertension were significantly more likely to be older than patients with newly diagnosed hypertension and normal BP.

Kaplan-Meier curves comparing survival outcome stratified by hypertension status were shown in Figure 1. Compared with patients of normal BP, all patients with hypertension had worse overall and ESCC-specific survival outcome ( $p=0.0223, p=0.0426)$. Similar association was observed in newly diagnostic hypertension $(p=0.0121$, $p=0.0103$ ). While no significant difference was found among patients with well-controlled, poorly-controlled hypertension and normal BP $(p=0.563, p=0.824)$.

\section{Comorbidities associated with ESCC survival outcomes}

The associations of ESCC prognosis and comorbidities including hypertension were available in Table 2. In univariate Cox proportional hazards regression model, hypertension (HR: 1.305, 95\% CI: 1.038, 1.641; HR: 1.270 , 95\% CI: 1.007, 1.600), cerebral-vascular disease (HR: 1.794, 95\% CI: 1.223, 2.633; HR: 1.704, 95\% CI: $1.146,2.534)$ and chronic obstructive pulmonary disease (COPD) (HR: 1.978, 95\% CI: 1.451, 2.696; HR: $1.937,95 \%$ CI: $1.413,2.656)$ were associated with higher risk of overall and ESCC-specific mortality.

\section{Multivariate-adjusted hazard ratios of hypertension for survival outcome}

We further put patient baseline characteristics, comorbidities and different hypertension status into the multiple Cox proportional hazard regression model. By stepwise variables selecting, the final models expressed as forest plots with HRs for overall and ESCC-specific mortality were shown in Figure 2. After adjustment in multivariate model, older patients (HR: 1.383, 95\% CI: 1.085, 1.763; HR:1.342, 95\% CI: 1.052, 1.714), deeper of tumor infiltration (HR: 1.677, 95\% CI: 1.414, 1.990; HR:1.710, 95\% CI: 1.436, 2.036), lymph node metastases (HR: 1.906, 95\% CI: 1.508, 2.410; HR:1.908, 95\% CI: 1.506, 2.418), hypertension (HR: 1.343, 95\% CI: 1.064 , 1.695; HR: $1.315,95 \%$ CI: $1.039,1.664)$ and COPD (HR: 1.802, 95\% CI: 1.321, 2.457; HR:1.764, 95\% CI: $1.285,2.420)$ were observed as increased risk for overall and ESCC-specific mortality. Patients with cerebralvascular comorbidity was positively associated with only overall mortality (HR: 1.498, 95\% CI: 1.012, 2.218). The similar results were observed that older age (HR: 1.385, 95\% CI: 1.065, 1.801; HR: 1.366, 95\% CI: 1.048, 1.781), deeper of tumor infiltration (HR: $1.549,95 \%$ CI: 1.282 , 1.870; HR: 1.541, 95\% CI: 1.276, 1.861), lymph node metastases (HR: 2.057, 95\% CI: 1.584, 2.672; HR: 2.069, 
Table 1: Distributions of baseline characteristics based on different hypertension status among patients with ESCC

\begin{tabular}{|c|c|c|c|c|c|c|}
\hline \multirow[b]{2}{*}{ Variables } & \multirow{2}{*}{$\begin{array}{c}\text { Without } \\
\text { HBP } \\
(n=471)\end{array}$} & \multirow{2}{*}{$\begin{array}{l}\text { Newly diagnostic } \\
\text { hypertension } \\
(n=317)\end{array}$} & \multicolumn{2}{|c|}{ History of hypertension } & \multirow[b]{2}{*}{$\chi^{2}$} & \multirow[b]{2}{*}{$p$} \\
\hline & & & $\begin{array}{l}\text { Well-controlled } \\
\quad(n=67)\end{array}$ & $\begin{array}{l}\text { Poorly-controlled } \\
\qquad(n=127)\end{array}$ & & \\
\hline Age (years) & & & & & 14.698 & 0.002 \\
\hline$<63$ & $224(47.56)$ & $138(43.53)$ & $20(29.85)^{*}$ & $41(32.28)^{*}$ & & \\
\hline$\geq 63$ & $247(52.44)$ & $179(56.47)$ & $47(70.15)$ & $96(67.72)$ & & \\
\hline Gender & & & & & 0.626 & 0.890 \\
\hline Male & $299(63.48)$ & $194(61.20)$ & $41(61.19)$ & $77(60.63)$ & & \\
\hline Female & $172(36.52)$ & $123(38.80)$ & $26(38.81)$ & $50(39.37)$ & & \\
\hline Family history & & & & & 1.881 & 0.597 \\
\hline No & $387(82.17)$ & $255(80.44)$ & $51(76.12)$ & $100(78.74)$ & & \\
\hline Yes & $84(17.83)$ & $62(19.56)$ & $16(23.88)$ & $27(21.26)$ & & \\
\hline Smoking & & & & & 3.975 & 0.264 \\
\hline No & $213(45.22)$ & $148(46.69)$ & $32(47.76)$ & $70(55.12)$ & & \\
\hline Yes & $258(54.78)$ & $169(53.31)$ & $35(52.24)$ & $57(44.88)$ & & \\
\hline Drinking & & & & & 0.957 & 0.812 \\
\hline No & $324(68.79)$ & $222(70.03)$ & $43(64.18)$ & $86(67.72)$ & & \\
\hline Yes & $147(31.21)$ & $95(29.97)$ & $24(35.82)$ & $41(32.28)$ & & \\
\hline $\begin{array}{l}\text { Depth of tumor } \\
\text { infiltration }\end{array}$ & & & & & 15.810 & 0.200 \\
\hline Tis & $6(1.27)$ & $5(1.58)$ & 0 & 0 & & \\
\hline $\mathrm{T} 1$ & $77(16.35)$ & $56(17.67)$ & $16(23.88)$ & $29(22.83)$ & & \\
\hline $\mathrm{T} 2$ & $90(19.11)$ & $56(17.67)$ & $16(23.88)$ & $28(22.05)$ & & \\
\hline $\mathrm{T} 3$ & $287(60.93)$ & $188(59.31)$ & $34(50.75)$ & $69(54.33)$ & & \\
\hline $\mathrm{T} 4$ & $11(2.34)$ & $12(3.79)$ & $1(1.49)$ & $1(4.00)$ & & \\
\hline $\begin{array}{l}\text { Lymph node } \\
\text { metastases }\end{array}$ & & & & & 5.629 & 0.131 \\
\hline No & $306(64.97)$ & $219(69.09)$ & $44(65.67)$ & $96(75.59)$ & & \\
\hline N1-N3 & $165(35.03)$ & $98(30.91)$ & $23(34.33)$ & $31(24.41)$ & & \\
\hline Diameter (cm) & & & & & 0.734 & 0.865 \\
\hline$<4.0$ & $267(56.69)$ & $179(56.47)$ & $38(56.72)$ & $77(60.63)$ & & \\
\hline$\geq 4.0$ & $204(43.31)$ & $138(43.53)$ & $29(43.28)$ & $50(39.37)$ & & \\
\hline $\begin{array}{l}\text { Vascular } \\
\text { infiltration }\end{array}$ & & & & & 2.990 & 0.393 \\
\hline No & $371(78.77)$ & $249(78.55)$ & 55 (82.09) & $108(85.04)$ & & \\
\hline Yes & $100(21.23)$ & $68(21.45)$ & $12(17.91)$ & $91(14.96)$ & & \\
\hline $\begin{array}{l}\text { Lymphatic vessel } \\
\text { infiltration }\end{array}$ & & & & & 0.653 & 0.884 \\
\hline No & $418(88.75)$ & $286(90.22)$ & $61(91.04)$ & $43(88.98)$ & & \\
\hline Yes & $53(11.25)$ & $31(9.78)$ & $6(8.96)$ & $14(11.02)$ & & \\
\hline
\end{tabular}

*There was significant difference between patients with normal blood pressure and history of hypertension, the same trend was also found between patients with new diagnosis and history of hypertension $(p<0.05)$.

95\% CI: 1.591, 2.692), newly diagnosed hypertension (HR: $1.414,95 \%$ CI: 1.095, 1.826; HR: 1.420, 95\% CI: $1.098,1.836)$ and COPD (HR: $1.741,95 \%$ CI: 1.233 , 2.456; HR: 1.699 , 95\% CI: 1.199, 2.407) were associated with increased risk of overall and ESCC-specific mortality in model where hypertension was divided into newly diagnosed and normal BP. However, when the hypertension was grouped into history of hypertension and normal BP, no association was found between history of hypertension and overall or ESCC-specific survival outcomes (HR:1.229, 95\% CI: 0.892, 1.694; HR: 1.132, 95\% CI: $0.812,1.578)$. 


\section{DISCUSSION}

The aim of our study was to investigate the relationship between hypertension and prognosis of patients with ESCC after surgical resection. To our knowledge, there was no previous studies conducted the relationships between ESCC prognosis and hypertension. The main finding of our study was that hypertension before esophagectomy shows an unfavorable prognosis for ESCC patients.

Hypertension, a chronic systemic disorder, has emerged as a pivotal factor of cardiovascular disease. It is notable that several studies have reported preoperative hypertension as a significant etiologic factor for the prognosis of cancers. Among patients with nasopharyngeal carcinoma, preoperative hypertension is an independent factor and results in poorer survival outcomes [24]. The similar trend has been found in patients with ovarian cancer [25]. In addition, hypertension alone reveals the increased risk of prior prognosis in bladder cancer after Bacilllus Calmette Guerin treatment [26]. It is also considered to be related to inferior prognosis of prostate cancer [27]. When age, race, tumor characteristics and breast cancer treatment were controlled, the presence of hypertension was associated with poorer breast cancer outcome [21].
If hypertension is truly causally associated with cancers, the biologic mechanisms linking hypertension and cancer should be elucidated further. However, the mechanisms are still not clear. In previous studies, the following possible mechanisms have been pointed out, but we have not found the subsequent studies focused on further discussion and confirmation. Based on the prior studies, increased expression of cytosolic calcium and inositol triphosphate involved in the pathogenesis of hypertension have been hypothesized to be involved in the early events of cell proliferation that may activate the endogenous oncogenes [28]. In addition, aberrant carcinogen has been found to bind to deoxyribonucleic acid in lymphocytes of hypertensive patients [29].

In recent studies, chronic hypoxia has been delineated as one possible mechanism that might be partly responsible for the increased cancer mortality in patients with hypertension [30]. Hypertension caused microvascular alterations in function and structure. Microvascular alterations, amplifying the haemodynamic load within microvascular network and inducing vasoconstriction within the microcirculation, could further lead to chronic endothelial injury and oxidative stress and promote tissue hypoxia [31]. Such adverse oxygenation
A

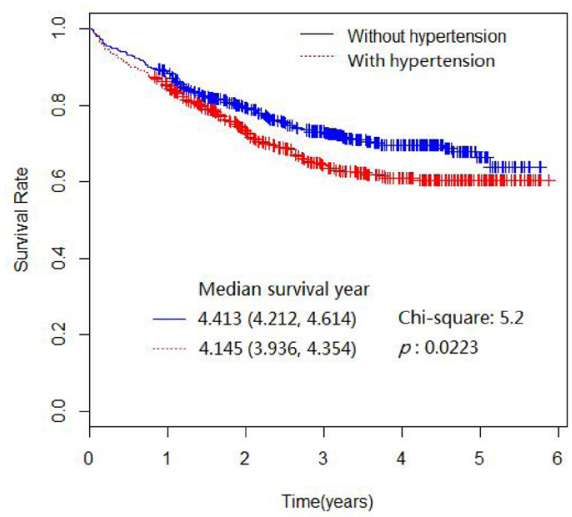

$$
\text { D }
$$

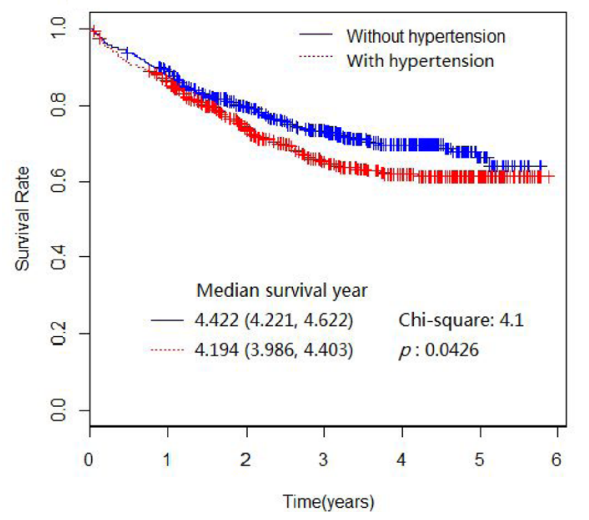

B

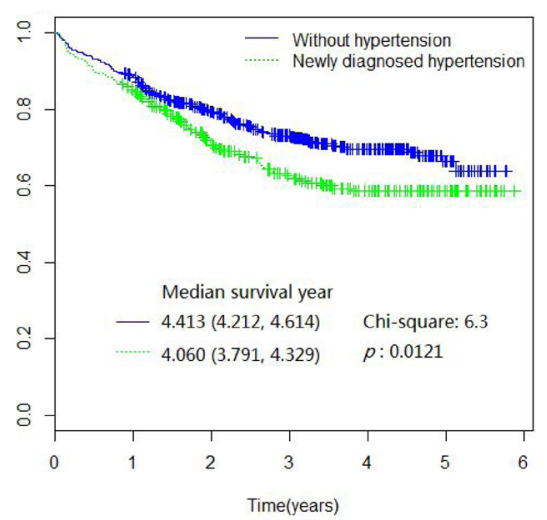

E

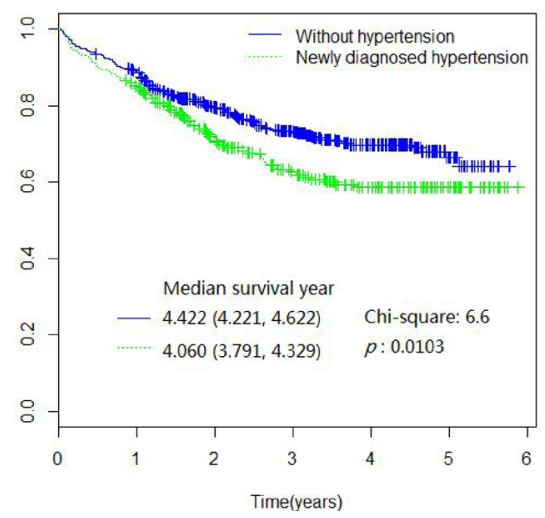

C

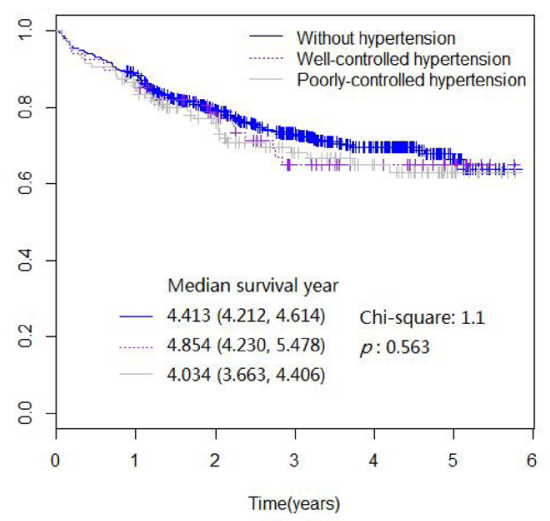

$\mathbf{F}$

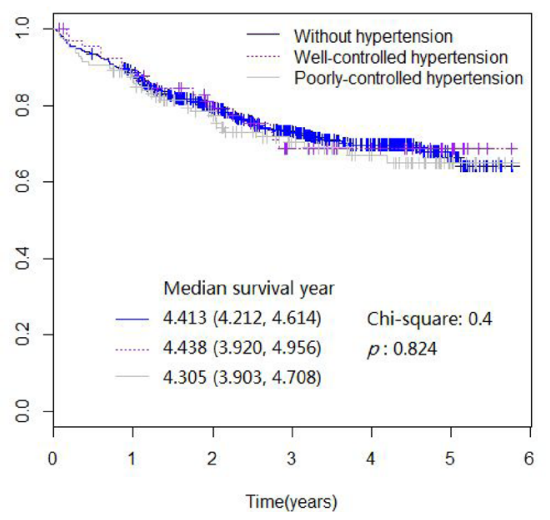

Figure 1: Kaplan-Meier survival curves for overall mortality (A-C) and ESCC-specific mortality (D-F), as stratified by different hypertension status. 
Table 2: Risk for mortality after surgery for ESCC among patients with and without hypertension and other comorbidities

\begin{tabular}{|c|c|c|c|c|c|c|c|c|}
\hline \multirow{2}{*}{ Comorbidities } & \multicolumn{2}{|c|}{ Overall } & \multirow{2}{*}{$\begin{array}{c}\text { HR } \\
(95 \% \mathrm{CI})\end{array}$} & \multirow{2}{*}{$p$} & \multicolumn{2}{|c|}{ Disease-specific } & \multirow{2}{*}{$\begin{array}{c}\text { HR } \\
(95 \% \mathrm{CI})\end{array}$} & \multirow{2}{*}{$p$} \\
\hline & Alive & Dead & & & Alive & Dead & & \\
\hline \multicolumn{9}{|l|}{ Hypertension } \\
\hline No & $343(50.22)$ & $128(42.81)$ & 1.00 (ref) & & $344(49.86)$ & $127(43.49)$ & 1.00 (ref) & \\
\hline Yes & $340(49.78)$ & $171(57.19)$ & $1.305(1.038,1.641)$ & 0.0228 & $346(50.14)$ & $165(56.51)$ & $1.270(1.007,1.600)$ & 0.0433 \\
\hline \multicolumn{9}{|l|}{ Heart disease } \\
\hline No & $644(94.29)$ & $290(96.99)$ & 1.00 (ref) & & $650(94.20)$ & $284(97.26)$ & 1.00 (ref) & \\
\hline Yes & $39(5.71)$ & $9(3.01)$ & $0.604(0.311,1.172)$ & 0.1359 & $40(5.80)$ & $8(2.74)$ & $0.548(0.271,1.107)$ & 0.5480 \\
\hline \multicolumn{9}{|c|}{$\begin{array}{l}\text { Cerebral-vascular } \\
\text { disease }\end{array}$} \\
\hline No & $643(94.14)$ & $270(90.30)$ & 1.00 (ref) & & $648(93.91)$ & $265(90.75)$ & 1.00 (ref) & \\
\hline Yes & $40(5.86)$ & $29(9.70)$ & $1.794(1.223,2.633)$ & 0.0028 & $42(6.09)$ & $27(9.25)$ & $1.704(1.146,2.534)$ & 0.0084 \\
\hline \multicolumn{9}{|l|}{ COPD } \\
\hline No & $624(91.36)$ & $251(83.95)$ & 1.00 (ref) & & $629(91.16)$ & $246(84.25)$ & 1.00 (ref) & \\
\hline Yes & $59(8.64)$ & $48(16.05)$ & $1.978(1.451,2.696)$ & $<0.0001$ & $61(8.84)$ & $46(15.75)$ & $1.937(1.413,2.656)$ & $<0.0001$ \\
\hline \multicolumn{9}{|l|}{ CKD } \\
\hline No & $671(98.24)$ & $293(97.99)$ & 1.00 (ref) & & $678(98.26)$ & $286(97.95)$ & 1.00 (ref) & \\
\hline Yes & $12(1.76)$ & $6(2.01)$ & $1.356(0.604,3.046)$ & 0.4603 & $12(1.74)$ & $6(2.05)$ & $1.395(0.621,3.132)$ & 0.4204 \\
\hline \multicolumn{9}{|l|}{ Diabetes } \\
\hline No & $648(94.88)$ & $278(92.98)$ & 1.00 (ref) & & $653(94.64)$ & 273 (93.49) & 1.00 (ref) & \\
\hline Yes & $35(5.12)$ & $21(7.02)$ & $1.327(0.852,2.068)$ & 0.2110 & $37(5.36)$ & $19(6.51)$ & $1.222(0.768,1.946)$ & 0.3977 \\
\hline \multicolumn{9}{|c|}{ Endocrine disease } \\
\hline No & $657(96.19)$ & $285(95.32)$ & 1.00 (ref) & & $661(95.80)$ & $282(96.58)$ & 1.00 (ref) & \\
\hline Yes & $26(3.81)$ & $14(4.68)$ & $1.173(0.686,2.007)$ & 0.5596 & $29(4.20)$ & $10(3.42)$ & $1.203(0.703,2.059)$ & 0.4995 \\
\hline \multicolumn{9}{|l|}{$\begin{array}{l}\text { Gastrointestinal } \\
\text { disease }\end{array}$} \\
\hline No & $654(95.75)$ & $289(96.66)$ & 1.00 (ref) & & $661(95.80)$ & $282(96.58)$ & 1.00 (ref) & \\
\hline Yes & $29(4.25)$ & $10(3.34)$ & $0.951(0.506,1.787)$ & 0.8763 & $29(4.20)$ & $10(3.42)$ & $0.976(0.519,1.834)$ & 0.9390 \\
\hline \multicolumn{9}{|l|}{ Anemia } \\
\hline No & $682(99.85)$ & $298(99.67)$ & 1.00 (ref) & & $689(99.86)$ & $291(99.66)$ & 1.00 (ref) & \\
\hline Yes & $1(0.15)$ & $1(0.33)$ & $2.540(0.356,18.10)$ & 0.3523 & $1(0.14)$ & $1(0.34)$ & $2.614(0.367,18.629)$ & 0.3376 \\
\hline \multicolumn{9}{|l|}{ Marasmus } \\
\hline No & $635(92.97)$ & $284(94.98)$ & 1.00 (ref) & & $641(92.90)$ & $278(95.21)$ & 1.00 (ref) & \\
\hline Yes & $48(7.03)$ & $15(5.02)$ & $0.754(0.449,1.268)$ & 0.2876 & $49(7.10)$ & $14(4.79)$ & $0.719(0.421,1.230)$ & 0.2290 \\
\hline
\end{tabular}

COPD: chronic obstructive pulmonary disease; CKD: chronic kidney disease.

status can promote tumor progression and contribute to an unfavorable prognosis for patient outcome [32].

Recently, as a meta-analysis having proved that the vascular endothelial growth factor (VEGF) overexpression associated with worse survival outcome in patients with ESCC, the connections of VEGF and hypertension could explain the major reason why ESCC patients with hypertension had the inferior prognosis [33]. VEGF has been considered as one of the most comprehensively prognostic biomarkers in a wide variety of tumors, including ESCC [34]. Thus far, it has been identified as one of the most potent stimulators involved in tumorassociated angiogenesis [35].
There was inconsistent association between history of hypertension and survival outcomes among cancer patients. In one prospective study, a negative association has been observed between history of hypertension and overall survival among patients with ovarian cancer [36]. Conversely, one retrospective study has failed to find an association between them among patients with ovarian cancer [37]. For endometrial cancer, there is an evidence that reduced mortality was associated with a history of hypertension [38, 39]. The authors of above studies of endometrial cancer hypothesized that antihypertensive treatment might be responsible for the reduced risk of mortality. It is plausible that antihypertensive medications 
could have a differential effect on a hormonal admixture in the patient's body and may influence the tumor microenvironment differently. However, this association is still lacking in tested biological mechanisms. In our study, we have not found the significant association between history of hypertension and survival outcome. The detailed mechanism should be further examined in the future study.

Through multiple analyses, patients with increased age have worse survival outcomes after esophagectomy. On the one hand, the operation is established in patients diagnosed with resectable tumors, which are in good clinical condition, whereas elder patients have relatively poor clinical condition and high risk of comorbidities [40]. From another point of view, we found that the percentage of hypertension distributed higher in elder patients. Unfortunately, the existing researches failed on considering hypertension as potential factors affecting prognosis among ESCC patients. Except for hypertension, cerebral-vascular disease and COPD were also found to increase the risk of ESCC mortality. Cerebral-vascular disease, a common risk factor of brain cancer prognosis, has been found to associated with lymph node metastasis in breast cancer patients [41]. COPD, an inflammatory respiratory disorder that related to inferior prognosis of lung cancer, has been identified that its pathogenesis is affected by tumor necrosis factor-related apoptosisinducing ligand (TRAIL), which is known as tumor necrosis factor superfamily member 10 (TNFSF10) [42]. Since there is not existing research about relationships between the above chronic disease and ESCC prognosis, the in-depth study should be further exploring. Besides, we found that Kaplan-Meier curves showed a tendency to be closer after the fifth year of follow-up. This might be the result of the gradually increased impact caused by age and above comorbidities during the long-term follow-up. In addition, patient lost to follow up happening gradually over time might be another reason.

Several limitations should be kept in mind of this study. First, this is a retrospective, observational study at a single institution. Second, we only considered patients with ESCC cause fewer patients diagnosed with esophageal adenocarcinoma or neuroendocrine carcinomas, which limited us to further comparative analyses. Third, we only focused on the preoperative hypertension, the hypertension that may occur during in the follow-up interval has not been detected. Fifth, the findings presented in this study cannot be directly extrapolated to the general populations as only patients who received esophagectomy were eligible for inclusion. Furthermore, the biologic mechanisms linking hypertension and ESCC should be elucidate in the next work.

In conclusion, we revealed the evidence that hypertension was associated with poorer prognosis among ESCC patients. From a public health perspective, these results were important because hypertension was highly prevalent worldwide and its control remained inadequate. Our analysis supported the relevance of public health programs aimed at improving the prognosis of patients with ESCC.

\section{MATERIALS AND METHODS}

\section{Patients}

Between August 2010 and December 2015, a consecutive series of 2040 patients who were diagnosed with EC and underwent esophagectomy were enrolled at Shanxi Provincial Cancer Hospital. Patients included in this study met the following criteria: (i) tumors histopathologically confirmed as ESCC; (ii) underwent curative esophagectomy; (iii) without neoadjuvant chemotherapy or radiotherapy; (iv) no other primary cancer or history of other cancers (v) with pathologically negative resection margin. Finally, a total of 982 patients were recruited in this study. The study was approved by the Ethics Committee of Shanxi Provincial Cancer

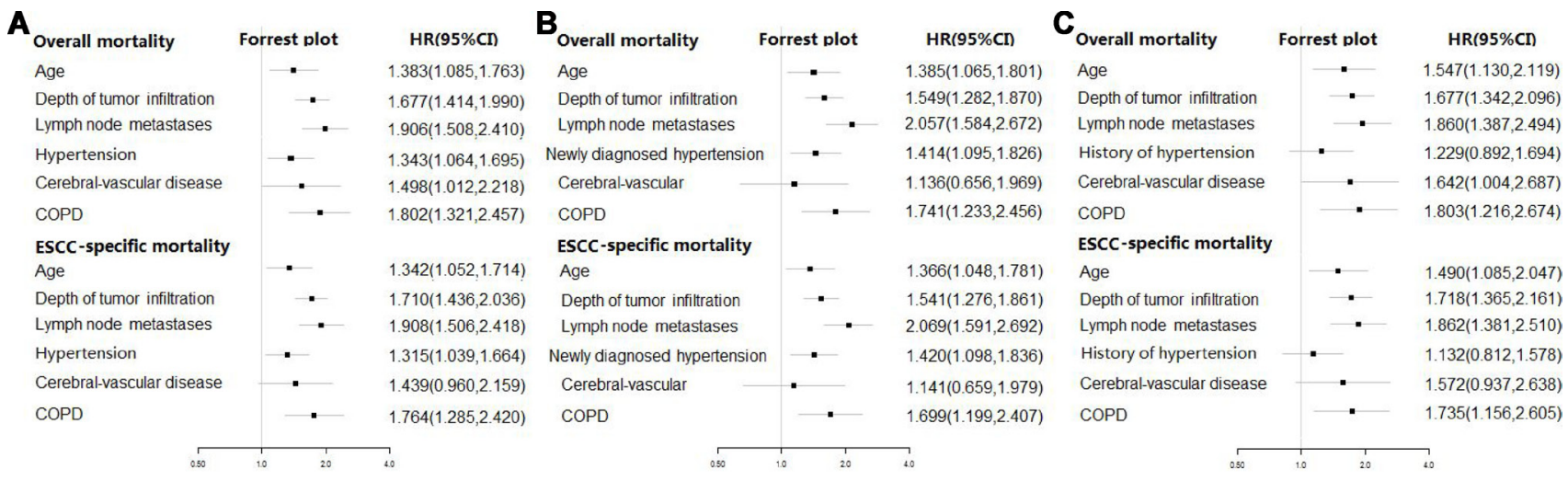

Figure 2: Forest plot of multivariate-adjusted hazard ratios (HRs) of hypertension for overall and ESCC-specific survival outcome. (A) hypertension was grouped into patients with hypertension and normal BP. (B) hypertension was divided into newly diagnosed hypertension and normal BP. (C) hypertension was grouped into patients with history of hypertension and normal BP. 
Hospital, and the written informed consents was obtained from all patients before surgery.

\section{Follow-up}

All patients were routinely followed up every 6 months for 3 years after undergoing curative surgery and annually thereafter. In this study, the follow-up was completed in December 2016. Patients were traced by telephone interviewers and the death information was confirmed by their family and local mortality registration department. Both overall and ESCC-specific survival time were recorded from the date of surgery until the date of death. Patients who were still alive at the last followup were treated as censored data with the censored rate of $70.63 \%$.

\section{Measurement and definition}

The general information was collected in a faceto-face interview using anonymous questionnaires by well-trained nurses at the time of enrollment. The questionnaire contains questions on birth, gender, alcohol consumption, current smoking and familial history of chronic diseases. Current alcohol users were defined as consuming alcohol at least once per month in the past year [43]. Current smokers were participants who have smoked at least one cigarette per day during the past month [44]. Information on history of chronic disease, comorbidity and tumor characteristics was obtained from the medical records. Primary tumor, regional lymph nodes and distant metastasis were coded based on the 7th edition of AJCC cancer staging manual [45]. Hypertension was defined as the average SBP $\geq 140 \mathrm{mmHg}$ and/or DBP $\geq 90 \mathrm{mmHg}$ according to the ambulatory BP monitor, as well as having history of hypertension or receiving antihypertension medication treatment $[46,47]$. BP were measured by portable BP monitors (HEM-7120, Omron, Liao Ning, China) every $30 \mathrm{~min}$ throughout the whole day while patients went about their normal activities and sleeping in the day of being hospitalized [48]. In this study, hypertension was categorised as newly diagnostic hypertension and history of hypertension. Patients with average SBP $\geq 140 \mathrm{mmHg}$ and/or DBP $\geq 90 \mathrm{mmHg}$ for the first time during this hospitalization phrase were defined as newly diagnosed hypertension. The history of hypertension was patients with prior diagnosed hypertension or taking antihypertension medical therapy. Among them, patients with BP measurement lower than 140/90 $\mathrm{mmHg}$ were defined as well-controlled hypertension, while BP measurement equal to or higher than $140 / 90 \mathrm{mmHg}$ were defined as poorly-controlled hypertension.

\section{Statistical analyses}

Statistical analyses were conducted with SAS statistical software (Version 9.3, SAS Institute, Inc., Cary, NC, USA). Categorical variables were described by frequencies and percentages and examined by Chisquare and rank test for unordered and ordinal categorical variables, respectively. Kaplan-Meier method and Logrank test were used to estimate survival curves and compare cumulative survival differences. We assessed the impact of hypertension on survival outcome using Cox proportional hazards regression model to calculate hazard ratios (HRs) and 95\% confidence intervals (CIs). The forest plot was used to reveal the regression results. Significance was two-sided and set at $p<0.05$.

\section{Abbreviations}

EC: esophageal cancer; ESCC: esophageal squamous cell carcinoma; BP: blood pressure; VEGF: vascular endothelial growth factor; SBP: systolic blood pressure; DBP: diastolic blood pressure; COPD: chorinic obstructive pulmonary disease; CKD: chronic kidney disease; AJCC: American Joint Committee on Cancer.

\section{Author contributions}

The study was designed by JL and GL; data were collected and entered by JL, YJ, LQ, YG, SZ, QZ and MC; data cleaning, analyzing, interpretation and manuscript preparation were undertaken by JL and GL; manuscript proofreading and polishing was made by JX and TW. This study was funded by the Natural Science Foundation of China (item no.81473073).

\section{ACKNOWLEDGMENTS}

Thanks for the support of Shanxi Provincial Cancer Hospital in Shanxi Province of China and the assistance of all interviewers and subjects who participated in our study.

\section{CONFLICTS OF INTEREST}

The authors declare that there are no conflicts of interests.

\section{REFERENCES}

1. Torre LA, Bray F, Siegel RL, Ferlay J, Lortet-Tieulent J, Jemal A. Global cancer statistics, 2012. CA Cancer J Clin. 2015; 65:87-108.

2. Zeng H, Zheng R, Guo Y, Zhang S, Zou X, Wang N, Zhang L, Tang J, Chen J, Wei K, Huang S, Wang J, Yu L, et al. Cancer survival in China, 2003-2005: a populationbased study. Int J Cancer. 2015; 136:1921-1930. 
3. Arnold M, Soerjomataram I, Ferlay J, Forman D. Global incidence of oesophageal cancer by histological subtype in 2012. Gut. 2015; 64:381-387.

4. Watson A. Operable esophageal cancer: current results from the West. World J Surg. 1994; 18:361-366.

5. Zhang DW, Cheng GY, Huang GJ, Zhang RG, Liu XY, Mao YS, Wang YG, Chen SJ, Zhang LZ, Wang LJ, De Zhang C, Yang L, Meng PJ, et al. Operable squamous esophageal cancer: current results from the East. World J Surg. 1994; 18:347-354.

6. WHO. Global Status Report on Non-communicable Disease 2010. Geneva, Switzerland: World Health Organization. 2011.

7. Radisauskas R, Kuzmickiene I, Milinaviciene E, Everatt R. Hypertension, serum lipids and cancer risk: A review of epidemiological evidence. Medicina (Kaunas). 2016; 52:89-98.

8. Haggstrom C, Rapp K, Stocks T, Manjer J, Bjorge T, Ulmer H, Engeland A, Almqvist M, Concin H, Selmer R, Ljungberg B, Tretli S, Nagel G, et al. Metabolic factors associated with risk of renal cell carcinoma. PLoS One. 2013; 8:e57475.

9. Choi MY, Jee SH, Sull JW, Nam CM. The effect of hypertension on the risk for kidney cancer in Korean men. Kidney Int. 2005; 67:647-652.

10. Stocks T, Van Hemelrijck M, Manjer J, Bjorge T, Ulmer H, Hallmans G, Lindkvist B, Selmer R, Nagel G, Tretli S, Concin H, Engeland A, Jonsson H, et al. Blood pressure and risk of cancer incidence and mortality in the Metabolic Syndrome and Cancer Project. Hypertension. 2012; 59:802-810.

11. Nagel G, Bjorge T, Stocks T, Manjer J, Hallmans G, Edlinger M, Haggstrom C, Engeland A, Johansen D, Kleiner A, Selmer R, Ulmer H, Tretli S, et al. Metabolic risk factors and skin cancer in the Metabolic Syndrome and Cancer Project (Me-Can). Br J Dermatol. 2012; 167:59-67.

12. Johansen D, Stocks T, Jonsson H, Lindkvist B, Bjorge T, Concin H, Almquist M, Haggstrom C, Engeland A, Ulmer H, Hallmans G, Selmer R, Nagel G, et al. Metabolic factors and the risk of pancreatic cancer: a prospective analysis of almost 580,000 men and women in the Metabolic Syndrome and Cancer Project. Cancer Epidemiol Biomarkers Prev. 2010; 19:2307-2317.

13. Bjorge T, Stocks T, Lukanova A, Tretli S, Selmer R, Manjer J, Rapp K, Ulmer H, Almquist M, Concin H, Hallmans G, Jonsson H, Stattin P, et al. Metabolic syndrome and endometrial carcinoma. Am J Epidemiol. 2010; 171:892-902.

14. Edlinger M, Strohmaier S, Jonsson H, Bjorge T, Manjer J, Borena WT, Haggstrom C, Engeland A, Tretli S, Concin H, Nagel G, Selmer R, Johansen D, et al. Blood pressure and other metabolic syndrome factors and risk of brain tumour in the large population-based Me-Can cohort study. J Hypertens. 2012; 30:290-296.
15. Haggstrom C, Stocks T, Rapp K, Bjorge T, Lindkvist B, Concin H, Engeland A, Manjer J, Ulmer H, Selmer R, Tretli S, Hallmans G, Jonsson H, et al. Metabolic syndrome and risk of bladder cancer: prospective cohort study in the metabolic syndrome and cancer project (Me-Can). Int J Cancer. 2011; 128:1890-1898.

16. Vatten LJ, Trichopoulos D, Holmen J, Nilsen TI. Blood pressure and renal cancer risk: the HUNT Study in Norway. Br J Cancer. 2007; 97:112-114.

17. Stocks T, Hergens MP, Englund A, Ye W, Stattin P. Blood pressure, body size and prostate cancer risk in the Swedish Construction Workers cohort. Int J Cancer. 2010; 127:1660-1668.

18. Haggstrom C, Stocks T, Ulmert D, Bjorge T, Ulmer H, Hallmans G, Manjer J, Engeland A, Nagel G, Almqvist M, Selmer R, Concin H, Tretli S, et al. Prospective study on metabolic factors and risk of prostate cancer. Cancer. 2012; 118:6199-6206.

19. Pelucchi C, Serraino D, Negri E, Montella M, Dellanoce C, Talamini R, La Vecchia C. The metabolic syndrome and risk of prostate cancer in Italy. Ann Epidemiol. 2011; 21:835-841.

20. Esposito K, Chiodini P, Capuano A, Bellastella G, Maiorino MI, Parretta E, Lenzi A, Giugliano D. Effect of metabolic syndrome and its components on prostate cancer risk: meta-analysis. J Endocrinol Invest. 2013; 36:132-139.

21. Braithwaite D, Tammemagi CM, Moore DH, Ozanne EM, Hiatt RA, Belkora J, West DW, Satariano WA, Liebman M, Esserman L. Hypertension is an independent predictor of survival disparity between African-American and white breast cancer patients. Int J Cancer. 2009; 124:1213-1219.

22. Zhu QL, Xu WH, Tao MH. Biomarkers of the metabolic syndrome and breast cancer prognosis. Cancers (Basel). 2010; 2:721-739.

23. Eskelinen TJ, Kotsar A, Tammela TL, Murtola TJ. Components of metabolic syndrome and prognosis of renal cell cancer. Scand J Urol. 2017; 51:435-41.

24. Yang P, Elhalawani H, Shi Y, Tang Y, Han Y, Zhao Y, Lou F, Jin H. A large-scale retrospective study of the overall survival outcome in nasopharyngeal carcinoma with hypertension in Chinese population. Oncotarget. 2017; 8:75577-75586. https://doi.org/10.18632/oncotarget.17483.

25. Minlikeeva AN, Freudenheim JL, Cannioto RA, Szender JB, Eng KH, Modugno F, Ness RB, LaMonte MJ, Friel G, Segal BH, Odunsi K, Mayor P, Zsiros E, et al, and Australian Ovarian Cancer Study Group, and Ovarian Cancer Association Consortium. History of hypertension, heart disease, and diabetes and ovarian cancer patient survival: evidence from the ovarian cancer association consortium. Cancer Causes Control. 2017; 28:469-486.

26. Dal Moro F, Bovo A, Crestani A, Vettor R, Gardiman MP, Zattoni F. Effect of hypertension on outcomes of highrisk patients after BCG-treated bladder cancer: a 
single-institution long follow-up cohort study. Medicine (Baltimore). 2015; 94:e589.

27. Xu H, Zhang LM, Liu J, Ding GX, Ding Q, Jiang HW. The association between overall survival of prostate cancer patients and hypertension, hyperglycemia, and overweight in Southern China: a prospective cohort study. J Cancer Res Clin Oncol. 2013; 139:943-951.

28. Meyer P. Increased intracellular calcium: from hypertension to cancer. J Hypertens. 1987; 5:S3-4.

29. Nordén A, Scherstén B, Thulin T, Pero RW, Bryngelsson C, Mitelman F. Letter: hypertension related to DNA repair synthesis and carcinogen uptake. Lancet. 1975; 2:1094.

30. Sharifi N, Farrar WL. Perturbations in hypoxia detection: a shared link between hereditary and sporadic tumor formation? Med Hypotheses. 2006; 66:732-735.

31. Vaupel P, Mayer A. Hypoxia in cancer: significance and impact on clinical outcome. Cancer Metastasis Rev. 2007; 26:225-239.

32. Dhani N, Fyles A, Hedley D, Milosevic M. The clinical significance of hypoxia in human cancers. Semin Nucl Med. 2015; 45:110-121.

33. Xia H, Shen J, Chen S, Huang H, Xu Y, Ma H. Overexpression of VEGF-C correlates with a poor prognosis in esophageal cancer patients. Cancer Biomark. 2016; 17:165-170.

34. Yang LP, Fu LC, Guo H, Xie LX. Expression of vascular endothelial growth factor $\mathrm{C}$ correlates with lymphatic vessel density and prognosis in human gastroesophageal junction carcinoma. Onkologie. 2012; 35:88-93.

35. Kerbel RS, Kamen BA. The anti-angiogenic basis of metronomic chemotherapy. Nat Rev Cancer. 2004; 4:423-436.

36. Schairer C, Gadalla SM, Pfeiffer RM, Moore SC, Engels EA. Diabetes, Abnormal Glucose, Dyslipidemia, Hypertension, and Risk of Inflammatory and Other Breast Cancer. Cancer Epidemiol Biomarkers Prev. 2017; 26:862-868.

37. Ferriss JS, Ring K, King ER, Courtney-Brooks M, Duska LR, Taylor PT. Does significant medical comorbidity negate the benefit of up-front cytoreduction in advanced ovarian cancer? Int J Gynecol Cancer. 2012; 22:762-769.

38. Ruterbusch JJ, Ali-Fehmi R, Olson SH, Sealy-Jefferson S, Rybicki BA, Hensley-Alford S, Elshaikh MA, Gaba AR, Schultz D, Munkarah AR, Cote ML. The influence of comorbid conditions on racial disparities in endometrial cancer survival. Am J Obstet Gynecol. 2014; 211:627. e1-627.e9.

39. Olson SH, Atoria CL, Cote ML, Cook LS, Rastogi R, Soslow RA, Brown CL, Elkin EB. The impact of race and comorbidity on survival in endometrial cancer. Cancer Epidemiol Biomarkers Prev. 2012; 21:753-760.

40. Nienhueser H, Kunzmann R, Sisic L, Blank S, Strowitzk MJ, Bruckner T, Jager D, Weichert W, Ulrich A, Buchler MW, Ott K, Schmidt T. Surgery of gastric cancer and esophageal cancer: Does age matter? J Surg Oncol. 2015; 112:387-395.

41. Sennerstam R, Schassburger KU, Stormby N, Wiksell H, Auer G. Axillary lymph node metastasis and survival in breast cancer patients with concurrent cardio-cerebralvascular disease. JRSM Short Rep. 2011; 2:12.

42. Haw TJ, Starkey MR, Nair PM, Pavlidis S, Liu G, Nguyen DH, Hsu AC, Hanish I, Kim RY, Collison AM, Inman MD, Wark PA, Foster PS, et al. A pathogenic role for tumor necrosis factor-related apoptosis-inducing ligand in chronic obstructive pulmonary disease. Mucosal immunology. 2016; 9:859-872.

43. Lasser K, Boyd JW, Woolhandler S, Himmelstein DU, McCormick D, Bor DH. Smoking and mental illness: A population-based prevalence study. JAMA. 2000; 284:2606-2610.

44. Xiang YT, Ma X, Lu JY, Cai ZJ, Li SR, Xiang YQ, Guo HL, Hou YZ, Li ZB, Li ZJ, Tao YF, Dang WM, Wu XM, et al. Alcohol-related disorders in Beijing, China: prevalence, socio-demographic correlates, and unmet need for treatment. Alcohol Clin Exp Res. 2009; 33:1111-1118.

45. Talsma K, van Hagen P, Grotenhuis BA, Steyerberg EW, Tilanus HW, van Lanschot JJ, Wijnhoven BP. Comparison of the 6th and 7th Editions of the UICC-AJCC TNM Classification for Esophageal Cancer. Ann Surg Oncol. 2012; 19:2142-2148.

46. Hodgkinson J, Mant J, Martin U, Guo B, Hobbs FD, Deeks JJ, Heneghan C, Roberts N, McManus RJ. Relative effectiveness of clinic and home blood pressure monitoring compared with ambulatory blood pressure monitoring in diagnosis of hypertension: systematic review. BMJ. 2011; 342:d3621.

47. Wang JG. Chinese Hypertension Guidelines. Pulse (Basel). 2015; 3:14-20.

48. Siu AL; U.S. Preventive Services Task Force. Screening for high blood pressure in adults: U.S. Preventive Services Task Force recommendation statement. Ann Intern Med. 2015; 163:778-786. 